\title{
Local structure at interfaces between hydride-forming metals: A case study of Mg-Pd nanoparticles by $x$-ray spectroscopy
}

\author{
L. Pasquini, ${ }^{1}$ F. Boscherini,${ }^{1,2}$ E. Callini, ${ }^{1}$ C. Maurizio,${ }^{2,3}$ L. Pasquali, ${ }^{4,5}$ M. Montecchi,,${ }^{4,5}$ and E. Bonetti ${ }^{1}$ \\ ${ }^{1}$ Department of Physics and CNISM, University of Bologna, v. Berti-Pichat 6/2, I-40127 Bologna, Italy \\ ${ }^{2}$ Consiglio Nazionale delle Ricerche, IOM-OGG, c/o ESRF GILDA CRG, BP 220, F-38043 Grenoble, France \\ ${ }^{3}$ Department of Physics, University of Padova, via Marzolo 8, I-35131 Padova, Italy \\ ${ }^{4}$ Department of Materials and Environmental Engineering, University of Modena and Reggio Emilia, v. Vignolese 905 , \\ I-41125 Modena, Italy \\ ${ }^{5}$ CNR-IOM, Area Science Park, s.s.14, km 163.5, I-34012 Basovizza (Trieste), Italy
}

(Received 10 December 2010; published 19 May 2011)

\begin{abstract}
The structure at the interface between elements or phases that exhibit different hydrogen $(\mathrm{H})$ binding energies exerts a profound influence on the thermodynamics of $\mathrm{H}$ in nanophase materials. In this paper, we study the local structure at the $\mathrm{Mg} / \mathrm{Pd}$ interface in $\mathrm{Mg}$ nanoparticles with partial Pd coating, and we map its evolution in response to annealing and $\mathrm{H}$ sorption. This task is accomplished by $\mathrm{x}$-ray photoelectron spectroscopy and $\mathrm{x}$-ray absorption spectroscopy, also including in situ experiments, with the support of crystallographic information from x-ray diffraction. It is shown that the initial Pd surface layer reacts with $\mathrm{Mg}$ at relatively low temperatures, leading to irreversible formation of a Mg-rich intermetallic phase $\mathrm{Mg}_{6} \mathrm{Pd}$. Due to the high $\mathrm{Mg}-\mathrm{H}$ binding energy, this phase reversibly transforms, upon $\mathrm{H}$ absorption, into a nanophase mixture of magnesium hydride and a Pd-rich intermetallic with $\mathrm{H}$ in solid solution, $\mathrm{MgPdH}_{\delta}$. These reversible structural changes are discussed with reference to recent calculations that highlight their relevance to the thermodynamics of the metal-hydride transition. The picture drawn here might be relevant to other multiphase materials presently investigated in the field of hydrogen-related science and technology.
\end{abstract}

DOI: 10.1103/PhysRevB.83.184111

PACS number(s): 61.46.-w, 61.05.cj, 64.70.-p, 68.35.Fx

\section{INTRODUCTION}

The metal-hydride reversible transformation stands out as a prominent example of first-order phase transition in solids. Many elements exhibit this phenomenon at temperatures and hydrogen $(\mathrm{H})$ pressures whose equilibrium values are mostly determined by the metal-H bond energy. The corresponding enthalpies of hydride formation $\Delta_{\mathrm{f}} H^{\text {hyd }}$ span from the large negative values of extremely stable hydrides such as $\mathrm{TiH}_{2}$, $\mathrm{ZrH}_{2}$, and $\mathrm{LaH}_{2}\left(-126\right.$ to $\left.-210 \mathrm{~kJ} / \mathrm{mol} \mathrm{H}_{2}\right)$, to the typical values of interstitial metallic hydrides $\mathrm{PdH}_{0.5}, \mathrm{VH}_{2}$, and $\mathrm{NbH}_{2}$ $\left(-40\right.$ to $-60 \mathrm{~kJ} / \mathrm{mol} \mathrm{H}_{2}$ ), up to the slightly negative enthalpies of high-pressure hydrides such as $\mathrm{NiH}_{0.5}$ and $\mathrm{AlH}_{3}$ (-6 to $-11 \mathrm{~kJ} / \mathrm{mol} \mathrm{H}_{2}$ ). Among all the elements, $\mathrm{Pd}$ was the first that attracted research activity, with the work of Graham nearly 150 years ago, ${ }^{1}$ and still remains the prototypical and most studied metal-hydrogen system. ${ }^{2}$ On the other hand, $\mathrm{Mg}$ is an appealing hydride former on account of its elevated $\mathrm{H}$-storage capacity (7.6 wt \%), abundance, and low cost, although its relatively high stability $\left(\Delta_{\mathrm{f}} H^{\mathrm{MgH}_{2}}=-75 \mathrm{~kJ} / \mathrm{mol} \mathrm{H}\right)_{2}$ poses severe constraints on the temperature for $\mathrm{H}$ release. In order to tailor the thermodynamics and the stability of hydride formation, intermetallic compounds (IMCs) of metals with different $\Delta_{\mathrm{f}} H^{\text {hyd }}$ were developed and extensively studied in the past. ${ }^{3}$

Nowadays, the desired advent of hydrogen as a future energy carrier has given new impetus to the research on its interaction with advanced materials, aimed at the development of efficient H-storage media, $\mathrm{H}$ sensors, and smart devices. In this context, it is of particular interest to study artificially created nanostructures where two or more phases having different $\Delta_{\mathrm{f}} H^{\text {hyd }}$ coexist on a nanometric length scale. The thermodynamics of these nanophase materials does not simply result from a weighted average of the components, since new physics emerges due to various interactions between them. For instance, it has been demonstrated that the stability of thin $\mathrm{MgH}_{2}$ films can be tuned by the elastic interaction with a constraining layer, in particular, $\mathrm{Pd}$ or $\mathrm{Ni}^{4}$ The extent to which such an appealing effect takes place strongly depends on the structure of the interface between the two metals: If they are immiscible, such as $\mathrm{Mg}$ and $\mathrm{Ti}$, the resulting elastic coupling is very weak and a quasifree behavior of $\mathrm{Mg}$ films occurs. ${ }^{5}$ Therefore, the local structure at the interface between the two hydride-forming metals plays a very important role in tailoring the overall $\mathrm{H}$-material interaction. The guiding rules adopted nowadays in the architecture of nanostructured hydrides resemble to some degree the principles of physical chemistry that lead to the discovery of conventional hydride-forming binary IMCs such as $\mathrm{Mg}_{2} \mathrm{Ni}, \mathrm{LaNi}_{5}$, FeTi, and $\mathrm{ZrCr}_{2} .{ }^{6}$ One rule is the combination of elements with markedly different $\Delta_{\mathrm{f}} H^{\text {hyd }}$ values. The second rule is to include one element which provides the ability to dissociate and/or recombine the $\mathrm{H}_{2}$ molecule, so that atomic $\mathrm{H}$ can be chemisorbed and diffused into the material. This issue is especially relevant for nanostructures based on $\mathrm{Mg}$, the catalytic properties of which are rather poor. Following this rule, Pd capping layers and $\mathrm{Pd}$ surface decoration have been applied to different Mg-based nanostructures, e.g., thin films and multilayers, ${ }^{4,7}$ nanoparticles (NPs), ${ }^{8}$ and nanoblades. ${ }^{9}$ Furthermore, Pd NPs serve as model materials to test size and quantum effects on the thermodynamics ${ }^{10}$ as well as on the kinetics ${ }^{11,12}$ of $\mathrm{H}$ sorption in metals. In fact, the microstructural features of modern nanostructures imply very short critical diffusion lengths for solid-state transformations such as the metal-hydride transition 
and alloying or intermixing at the interfaces, and therefore the associated kinetics time scales become fast at strongly reduced temperatures with respect to conventional bulklike materials.

In this paper we use two x-ray spectroscopy techniques to gain insight, at the local atomic level, of the changes in structure and bonding which occur during annealing and $\mathrm{H}$ sorption at the $\mathrm{Mg} / \mathrm{Pd}$ interface in Pd-decorated $\mathrm{Mg}$ NPs. Specifically we employ $\mathrm{x}$-ray photoelectron spectroscopy (XPS) and x-ray absorption fine structure (XAFS). The analysis of the intensity and chemical shifts of $\mathrm{Pd}$ and $\mathrm{Mg}$ core-level XPS spectra after successive sputtering cycles is used to correlate the changes in local environment with the depth from the surface-near region for variously treated NPs. $\mathrm{Pd} K$-edge XAFS is used to quantitatively describe the local structure of $\mathrm{Pd}$-containing phases in different equilibrium states. In situ experiments are also carried out to track the transition between these states induced by temperature and $\mathrm{H}_{2}$ pressure variations. It is well known that XAFS is particularly suited to follow local structural changes in nanostructured materials since the physical phenomenon upon which the technique is based is inherently local and does not depend on the presence of long-range order, which is the case of powder X-ray diffraction (XRD). In this respect, it should be emphasized that XRD and XAFS do not necessarily probe the same portion of a sample: Powder XRD is sensitive only to the parts of the sample exhibiting long-range order while XAFS probes the average structure of all the absorbing atoms. Hence, the results of an XAFS experiment are of particular interest in comparison to XRD investigations which we have previously reported on the same samples. ${ }^{13}$

It will be shown that irreversible transformations first occur upon annealing, leading to a Mg-rich IMC at the NPs surface. Subsequently, the competition between $\mathrm{Mg}-\mathrm{Pd}$ bond energy, $\mathrm{Mg}-\mathrm{H}$ bond energy, and $\mathrm{H}_{2}$ gas entropy during $\mathrm{H}$ sorption results in a reversible transformation between $\mathrm{Pd}$ local environments characterized by markedly different values of the Pd-Pd nearest-neighbor distance and of Pd-Mg coordination numbers. This picture, where $\mathrm{Mg}$ plays the role of the element with more negative $\Delta_{\mathrm{f}} H^{\text {hyd }}$, reflects the different hydride formation enthalpies of $\mathrm{Mg}$ and $\mathrm{Pd}$ and relies on the complex $\mathrm{Mg}$-Pd binary phase diagram characterized by several IMCs. Therefore, the scenario examined here might be relevant to other binary or multiphase materials with similar characteristics appealing for hydrogen-related science and technology, such as $\mathrm{MgH}_{2} / T M \mathrm{H}_{2}$ multilayers $(T M=$ transition metal), ${ }^{4,14}$ La-Ni based thin films, Pd/TM nanoscale bilayers, ${ }^{15}$ and metal-hydride switchable mirrors. ${ }^{16}$

\section{SAMPLE PREPARATION AND EXPERIMENTAL}

$\mathrm{Mg} / \mathrm{MgO}$ core-shell NPs were synthesized by inert gas condensation and were subsequently surface decorated by in situ evaporation of $\mathrm{Pd}$, as described in Ref. 8. Transmission electron microscopy (TEM) observations show that the NPs are single crystals with a hexagonal-close-packed (hcp) structure and an average size of $\sim 450 \mathrm{~nm}$, uniformly coated by a 4-5 nm thick MgO shell. ${ }^{8}$ According to TEM analysis, $\mathrm{Pd}$ decoration consists in face-centered-cubic (fcc) clusters, 3-4 $\mathrm{nm}$ in diameter, located on a portion of the $\mathrm{MgO}$ shell.

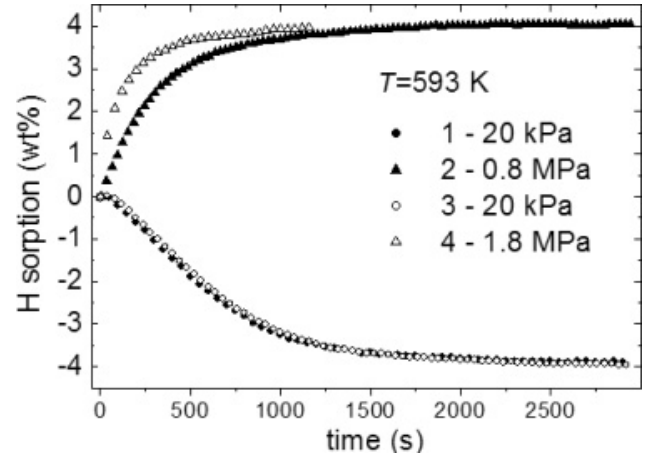

FIG. 1. Transformation kinetics measured by the volumetric Sieverts apparatus on sample 3, after the activation and hydrogenation treatment at $638 \mathrm{~K}$ and $1.8 \mathrm{MPa}_{2}$ pressure. Positive (negative) values of $\mathrm{H}$ sorption correspond to metal-hydride (hydride-metal) transformation path. The numbers indicate the transformation sequence. The last $\mathrm{H}$-absorption step at $1.8 \mathrm{MPa}$ leaves the sample in the hydride state for subsequent XAFS measurements.

In order to track the local structure at the $\mathrm{Mg} / \mathrm{MgO} / \mathrm{Pd}$ interface, we studied three samples obtained from the same NP batch: Sample 1 consists of the as-prepared Mg-Pd NPs; sample 2 was obtained after 1 -h annealing at $623 \mathrm{~K}$ under dynamic vacuum $(1 \mathrm{~Pa})$; and sample 3 , representing the hydrogenated state, was subjected to one activation treatment at $638 \mathrm{~K}$ under 1.8- $\mathrm{MPa} \mathrm{H}_{2}$ pressure in a volumetric Sieverts apparatus, followed by two $\mathrm{H}$ release and uptake cycles at $593 \mathrm{~K}$. The corresponding metal-hydride transformation kinetics is displayed in Fig. 1. The different samples and their temperature and pressure history are listed in Table I.

XRD was carried out with a Rigaku DMAX-IIIC BraggBrentano diffractometer, employing $\mathrm{Cu} K \alpha$ radiation and a graphite monochromator in the diffracted beam. The XRD patterns were quantitatively analyzed using the Rietveld full profile fitting method implemented in the program MAUD. ${ }^{17}$

XPS was performed with nonmonochromatic $\mathrm{Mg} \mathrm{K \alpha}$ photons $(h v=1253.6 \mathrm{eV})$ from a Vacuum Generators XR3 dual anode source operated at $15 \mathrm{kV}, 18 \mathrm{~mA}$. Photoemission data were collected with a double-pass Perkin Elmer PHI 15-255G cylindrical-mirror electron analyzer operated at constant pass energy. The analyzer resolution was set to $1 \mathrm{eV}$. The spectra are reported as a function of the electron binding energy $(\mathrm{BE})$, referenced to the $\mathrm{C}_{1 s}$ signal $(284.8 \mathrm{eV})$ of adventitious carbon. Moreover, a background subtraction was applied and replicas due to $\mathrm{Mg} K \alpha$ satellites were removed from spectra. ${ }^{18}$ In order to investigate the subsurface composition, the NPs were subjected to a sputtering with $\mathrm{Ar}^{+}$ions $(5 \mathrm{kV}, 25 \mathrm{~mA}$ for $3 \mathrm{~h})$.

XAFS measurements at the $\mathrm{Pd} K$ edge were carried out at the GILDA beamline of the European Synchrotron Radiation Facility (ESRF) in Grenoble, France. ${ }^{19}$ A Si(311) independent crystal monochromator with dynamic sagittal focusing was employed. ${ }^{20}$ Harmonics rejection was achieved by using two grazing incidence Pt-coated mirrors and by crystal detuning. All measurements were performed in transmission geometry using argon-filled ionization chambers to record the energy dependence of the incident and transmitted x-ray fluxes. In order to ensure lateral homogeneity of the measured sample, the NPs were gently mixed with dry boron nitride powder inside an agate mortar, and then pressed at room temperature to obtain 
TABLE I. Sample history and phase composition determined from Rietveld analysis of XRD profiles.

\begin{tabular}{|c|c|c|c|c|c|c|c|c|c|}
\hline Sample & Preparation/treatment & $\begin{array}{c}\mathrm{Mg} \\
\text { wt \% }\end{array}$ & $\begin{array}{c}\mathrm{MgH}_{2} \\
\text { wt \% }\end{array}$ & $\begin{array}{c}\mathrm{Mg}_{6} \mathrm{Pd} \\
\text { wt \% }\end{array}$ & $\begin{array}{c}\mathrm{Mg}_{3} \mathrm{Pd} \\
\text { wt \% }\end{array}$ & $\begin{array}{c}\mathrm{Mg}_{5} \mathrm{Pd}_{2} \\
\text { wt \% }\end{array}$ & $\begin{array}{l}\mathrm{MgPd} \\
\text { wt \% }\end{array}$ & $\begin{array}{c}\mathrm{Pd} \\
\text { wt } \%\end{array}$ & $\begin{array}{l}\mathrm{MgO} \\
\text { wt \% }\end{array}$ \\
\hline 1 & as-prepared Mg-Pd NPs & $88(1)$ & - & - & - & - & - & $10(1)$ & $2(1)$ \\
\hline 2 & Annealed for $1 \mathrm{~h}$ at $623 \mathrm{~K}$ & $56(1)$ & - & $17(1)$ & - & - & - & - & $27(3)$ \\
\hline 3 & $\mathrm{H}$ absorption at $593 \mathrm{~K}, 1.8 \mathrm{MPa}$ & $1.0(3)$ & $58(5)$ & - & $2.0(3)$ & $1.3(3)$ & $6.7(7)$ & - & $31(3)$ \\
\hline $3^{*}$ & Sample $3+$ in situ $\mathrm{H}$ desorption & $54(1)$ & - & $18(1)$ & - & - & - & - & $28(3)$ \\
\hline
\end{tabular}

disk-shaped pellets of $4 \mathrm{~mm}$ diam. Extended XAFS (EXAFS) spectra were measured in the energy range $24.15-25.85 \mathrm{keV}$, with a step in wave number $k$ smaller than $0.05 \AA^{-1}$. All EXAFS spectra were collected at $80 \mathrm{~K}$ in order to reduce thermal damping of the signal and increase the available $k$ space.

X-ray absorption near-edge structure (XANES) spectra were measured in the energy range $24.30-24.44 \mathrm{keV}$. XANES spectra of samples 1 and 3 were collected above room temperature (RT), under high vacuum conditions $\left(10^{-2} \mathrm{~Pa}\right)$, in order to follow in situ the local structure changes during annealing and $\mathrm{H}$ desorption. For these measurements, the sample pellet was mounted on a resistively heated copper sample holder, whose temperature was monitored by a chromel alumel thermocouple and controlled by a proportional-integral-derivative feedback loop. After this experiment, sample 3 becomes representative of the dehydrogenated state, and will be referred to as sample $3^{*}$ (Table I).

EXAFS spectra were analyzed with the ATHENA and ARTEMIS packages. ${ }^{21}$ EXAFS oscillations were extracted from the raw spectra using a low-distance cutoff of $1 \AA$ in the $k^{2}$ weighted Fourier transform and using a cubic spline. As a starting point for nonlinear fitting of the spectra, EXAFS signals were calculated using the FEFF 8.20 code $^{22}$ using crystallographic structures as input. Further details on the data treatment and fitting procedure will be given in the following sections.

\section{RESULTS}

\section{A. Long-range structure}

The XRD patterns of samples 1, 2, and 3, reported in Fig. 2, allow to determine the crystallographic phase composition (Table I) and microstructure parameters following annealing and hydrogenation. The XRD patterns provide the necessary starting point for the quantitative analysis and interpretation of XPS and XAFS spectra.

In the as-prepared state of sample 1, Pd appears in the fcc structure with very broad reflections. Its relative amount is estimated to be 10(1) wt \%. The Pd crystallite size determined from XRD line broadening is $D_{\mathrm{Pd}}=4(1) \mathrm{nm}$. Upon annealing (sample 2), the formation of the $\mathrm{Mg}_{6} \mathrm{Pd}$ IMC occurs, with quite narrow reflections, yielding an isotropic crystallite size $D_{\mathrm{Mg}_{6} \mathrm{Pd}}=70(10) \mathrm{nm}$. The formation of the IMC is accompanied by an increase in the fraction of oxide $\mathrm{MgO}$, characterized by an ultrafine crystallite size $D_{\mathrm{MgO}}=6(1) \mathrm{nm}$. In the hydrogenated state of sample 3 , cubic MgPd constitutes the main Mg-Pd intermetallic phase, even though small amounts of $\mathrm{Mg}_{3} \mathrm{Pd}$ and $\mathrm{Mg}_{5} \mathrm{Pd}_{2}$ are detected. A crystallite size $D_{\mathrm{MgPd}}=12(2) \mathrm{nm}$ is determined from the width of $\mathrm{MgPd}$ reflections, clearly broader than for other $\operatorname{Mg}_{x} \mathrm{Pd}_{y}$ intermetallics. Concerning the entire Mg-Pd
$\mathrm{NP}$ system, we observe that the $\mathrm{Mg}+\mathrm{H}_{2} \rightarrow \mathrm{MgH}_{2}$ metalhydride transformation is almost complete: Only trace amounts of metallic hcp $\mathrm{Mg}$ are visible in the XRD profile of sample 3 [Fig. 2(c), Table I]. Further, the Mg-Pd NPs display fully reversible and stable $\mathrm{H}$-sorption kinetics, as demonstrated in Fig. 1 and reported for similar samples with slightly different Pd content. ${ }^{8}$ This behavior is accompanied by a reversible transformation of the Pd-containing phases. In fact, in the XRD profile of dehydrogenated sample $3^{*}$ only the $\mathrm{Mg}_{6} \mathrm{Pd}$ IMC is detected (not shown; see Table I). The amount of $\mathrm{MgO}$ remains

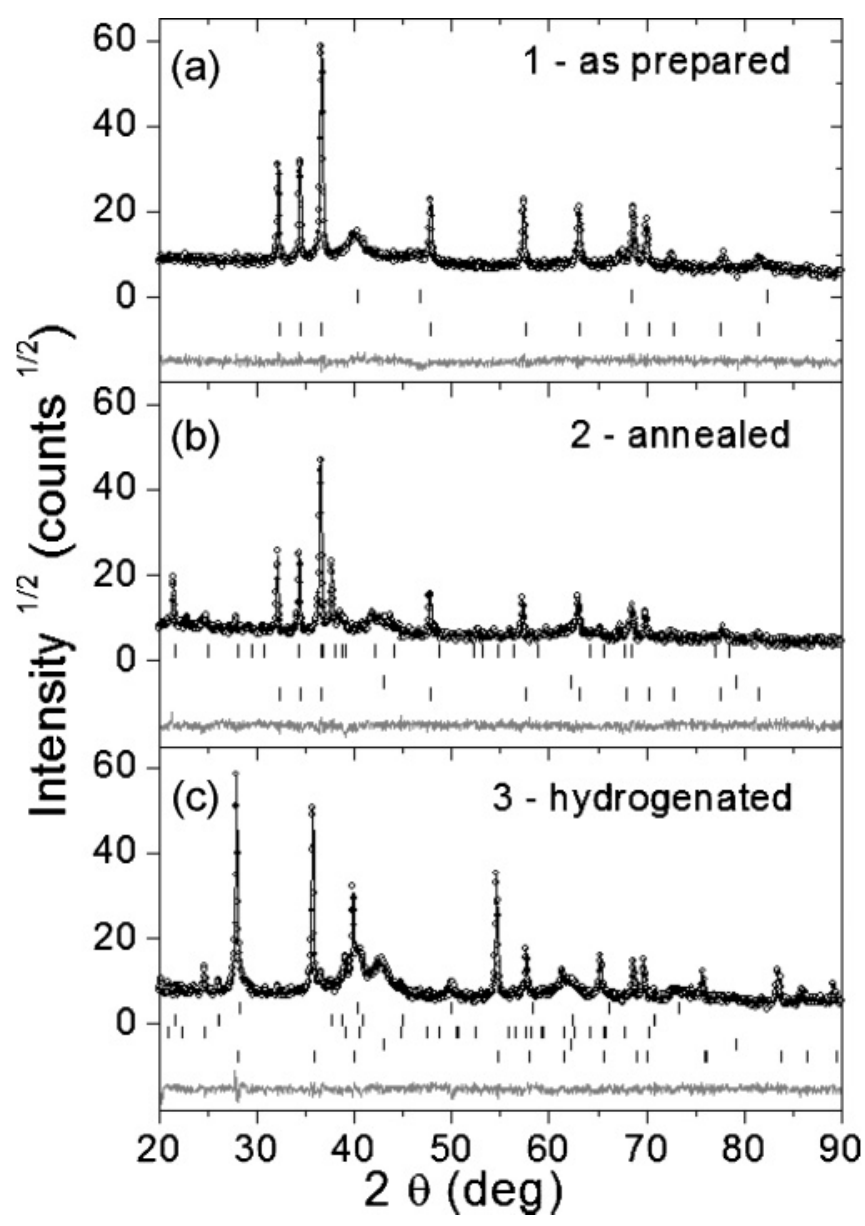

FIG. 2. XRD profiles of Mg-Pd NP samples 1-3. The raw data are represented by open symbols, the Rietveld fit by the continuous black line, and the residual (vertically shifted by -15 ) by the gray line. The crystallographic phases corresponding to the rows of vertical bars, ordered from top to bottom for each graph, are as follows: fcc Pd, hcp $\mathrm{Mg}$ (sample 1); $\mathrm{Mg}_{6} \mathrm{Pd}, \mathrm{MgO}$, hcp $\mathrm{Mg}$ (sample 2); $\mathrm{MgPd}, \mathrm{Mg}_{5} \mathrm{Pd}_{2}$, $\mathrm{Mg}_{3} \mathrm{Pd}, \mathrm{MgO}, \mathrm{MgH}_{2}$ (sample 3). A residual trace of hcp $\mathrm{Mg}$ is visible in sample 3 . 

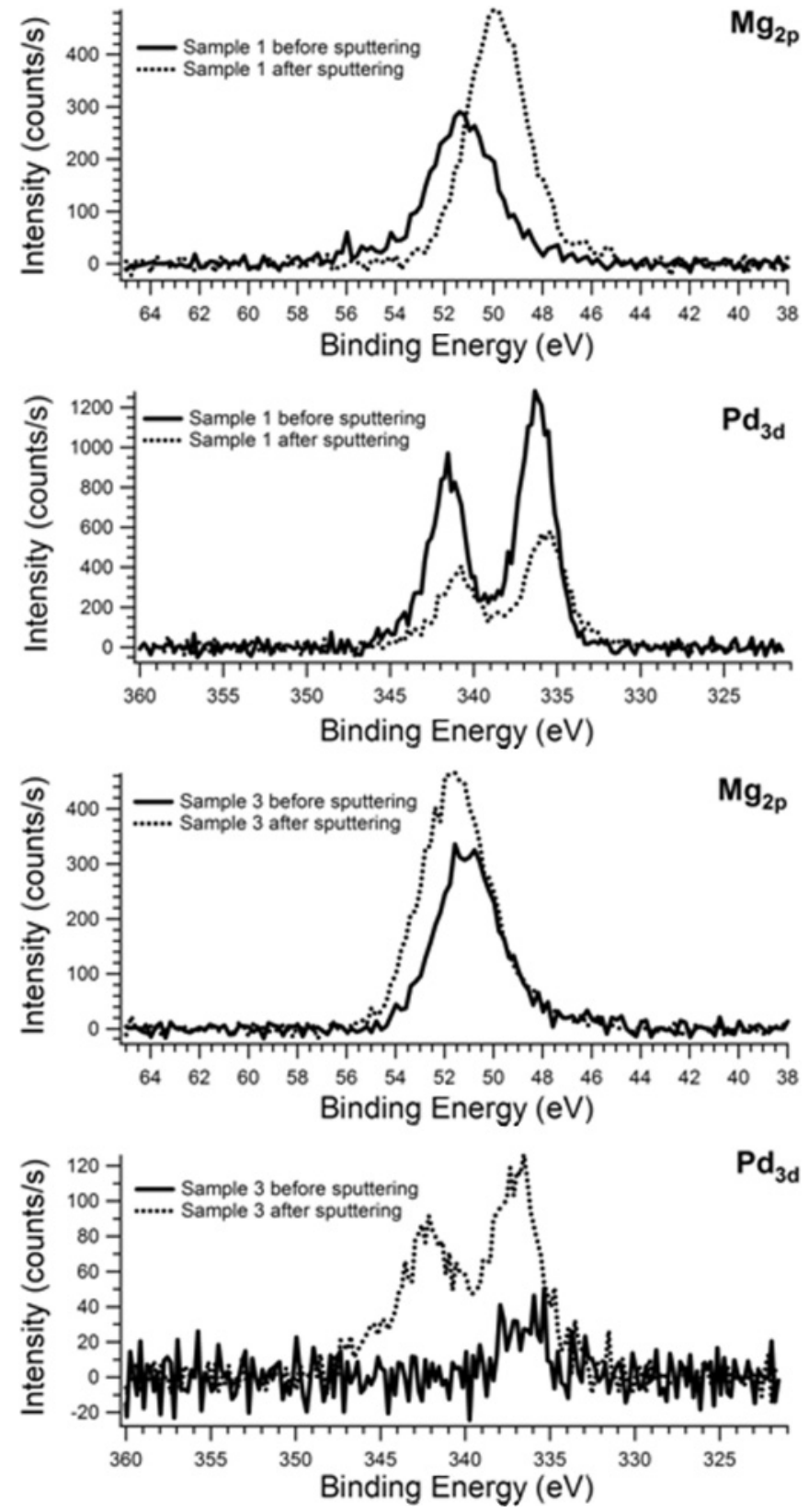

FIG. 3. $\mathrm{Mg}_{2} p$ and $\mathrm{Pd}_{3} d$ XPS signals for sample 1 and sample 3, before (continuous line) and after (dotted line) 3-h $\mathrm{Ar}^{+}$sputtering.

constant over subsequent $\mathrm{H}$-sorption cycles, resulting in a constant H-storage capacity of $\sim 4.2 \mathrm{wt} \%$ at saturation (Fig. 1).

\section{B. Composition and local environment of near-surface layers}

In order to study the variation of the composition and atomic environment of the near-surface layers induced by $\mathrm{H}$ sorption, we performed XPS measurements on samples 1 and 3. A qualitative assessment of depth-related changes was achieved by $\mathrm{Ar}^{+}$sputtering. Energy distribution curves from the $\mathrm{Mg} 2 p$ and $\mathrm{Pd} 3 d$ core levels before and after sputtering are reported in Fig. 3 for the two samples. Spin-orbit splitting is evident for the $\mathrm{Pd} 3 d$ levels while the energy resolution is not sufficient to observe it for the $\mathrm{Mg} 2 p$ levels.

In the as-prepared sample 1, the energy position of the $\mathrm{Mg}$ $2 p$ peak is shifted to higher $\mathrm{BE}$ (at $51.2 \mathrm{eV}$ ) with respect to metallic $\mathrm{Mg}$ (49.8 eV, Ref. 23) and corresponds to oxidized $\mathrm{Mg}$ atoms of the 5-nm-thick $\mathrm{MgO}$ shell. After $\mathrm{Ar}^{+}$sputtering, the $\mathrm{Mg} 2 p$ peak moves toward lower BE (at $49.9 \mathrm{eV}$ ) while its intensity increases. The $\mathrm{Pd} 3 d$ peaks are similarly shifted toward lower BE after $\mathrm{Ar}^{+}$sputtering $\left(\mathrm{Pd} 3 d_{5 / 2}\right.$ at $\left.335.5 \mathrm{eV}\right)$, but with decreased intensity. Therefore, it appears that $\mathrm{Ar}^{+}$ sputtering removes part of the $\mathrm{MgO}$ shell and of the Pd clusters from the NP surface, exposing metallic Mg from the NP core. The slightly higher BE of the $\mathrm{Pd} 3 d$ peaks before sputtering can be explained by a partial oxidation of the Pd clusters. ${ }^{24}$ Since direct evidence of Pd oxidation does not emerge from XRD and XAFS measurements (see below), we expect it to affect only the very surface of Pd clusters, to which XPS is extremely sensitive due to the short escape depth of photoelectrons with $\approx 1 \mathrm{keV}$ kinetic energy.

In the hydrogenated sample 3, we notice that the $\mathrm{Pd}$ $3 d$ signal is extremely weak before sputtering, while after sputtering it becomes clearly visible, though with reduced intensity when compared to the as-prepared sample 1 . It must be reminded that in this sample the main phases are $\mathrm{MgH}_{2}$, $\mathrm{MgO}$, and $\mathrm{MgPd}$ (see Table I). On this basis, the shift of $\mathrm{Pd}$ $\mathrm{BE}$ position $\left(\mathrm{Pd} 3 d_{5 / 2}\right.$ at $\left.336.9 \mathrm{eV}\right)$, with respect to the value of $335 \mathrm{eV}$ expected for pure $\mathrm{Pd}$, arises from the redistribution of the screening charge due to alloying with $\mathrm{Mg}$, as reported by Zlotea et al. ${ }^{23}$ This conclusion would remain valid even taking into account the possibility of composition changes induced by preferential sputtering of light $\mathrm{Mg}$ atoms. As for the $\mathrm{Mg} 2 p$ profile, we cannot discriminate between XPS signals from $\mathrm{MgO}$ and $\mathrm{MgH}_{2}$, because the two phases have very close Mg $2 p$ BEs. ${ }^{25}$ Therefore, differently from the as-prepared sample 1, where metallic hcp Mg constitutes the NP core, we do not expect a significant shift of the $\mathrm{Mg} 2 p$ peak due to $\mathrm{Ar}^{+}$ sputtering of the $\mathrm{MgO}$ shell. This is indeed the case, as revealed by the minor changes displayed in Fig. 3 for the $\mathrm{Mg} 2 p$ profile.

\section{Pd local structure}

XAFS spectra were collected on all samples and also on a reference coarse-grained $\mathrm{Pd}$ foil, for comparison. Figure 4 reports the $k$-weighted raw EXAFS spectra $\chi(k)$ after background subtraction, which extend up to $20 \AA^{-1}$. The EXAFS spectrum of sample 1 is similar to that of the $\mathrm{Pd}$ foil, however, we note that high-frequency components are damped so that the overall spectrum has broader features. The EXAFS spectra of the other samples are quite different from sample 1 and exhibit very weak oscillations in the high- $k$ range, reflecting a severe modification of the local structure around the Pd absorber following annealing and $\mathrm{H}$ sorption. We note that the EXAFS spectra of the annealed (sample 2) and dehydrogenated (sample $3^{*}$ ) samples are quite similar. The magnitudes of the Fourier transforms (FTs) of the EXAFS functions are displayed in Fig. 5. A $k^{3}$ weight was used for the transforms and no phase-shift correction was applied. The transform range was $4-19 \AA^{-1}$ for the Pd foil and sample 1 , while the $2.5-14 \AA^{-1}$ range was selected for the other samples since they exhibit weaker high- $k$ oscillations. Differences and similarities in the FTs correspond to those already illustrated for the raw EXAFS spectra.

A small peak at $R \sim 1 \AA$ is visible in the FT of the EXAFS spectra (Fig. 5) of samples 2, 3, and 3*. This distance is too short to be related to any physically meaningful 


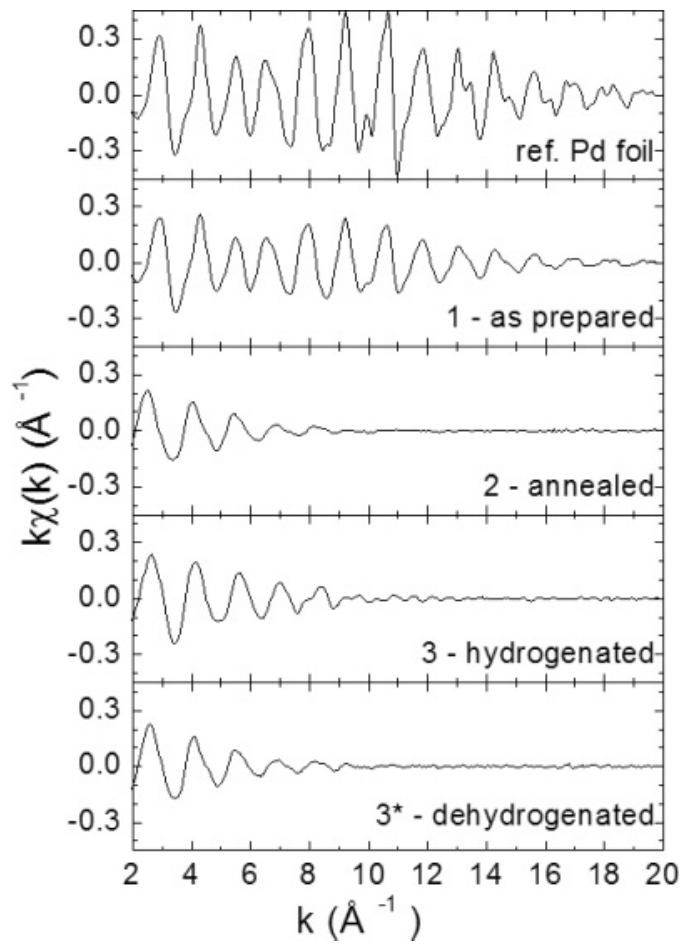

FIG. 4. $k$-weighted raw EXAFS spectra after background subtraction, measured at $80 \mathrm{~K}$ in transmission mode for a reference $\mathrm{Pd}$ foil and the Mg-Pd NP samples 1-3*.

interatomic distance. Rather, this low $R$ peak is the signature of the presence of double-electron excitations in the $\mathrm{x}$-ray absorption spectrum. This effect becomes evident in samples 2, 3, and $3^{*}$ since in these cases the EXAFS oscillations are significantly weaker than in the case of the Pd foil or sample 1. Double-electron excitations, i.e., the excitation of two core electrons following the absorption of a single $\mathrm{x}$-ray photon, are known to give contributions to the x-ray absorption cross section. These contributions are quite weak, so that they were first detected in spectra of monoatomic gasses in which EXAFS oscillations are absent ${ }^{26}$ and later in amorphous solids $^{27}$ and simple molecules ${ }^{28}$ in which they are weak. In crystalline solids, double-excitation contributions were initially observed only in the spectral regions in which EXAFS oscillations are very weak. ${ }^{29}$ It is nowadays accepted that double-electron excitations can give detectable contributions to $\mathrm{x}$-ray absorption spectra even in crystalline solids. ${ }^{30}$ The main effect of these excitation is to introduce weak steplike discontinuities in the atomic background, leading to small peaks in the FT spectra at low $R$. Given the relative weakness of the EXAFS oscillations in samples 2, 3, and $3^{*}$ it is not surprising that a low $R$ peak is visible only in these samples. Since we base our analysis on a Fourier filtering approach of the structurally significant peaks in the range $R>1.5 \AA$, we do not expect the presence of the low $R$ peak to adversely affect the reliability of the local atomic structure determination.

Following the information derived from XRD, the scattering paths considered for the EXAFS data analysis were calculated from the fcc Pd structure in the case of sample 1 and Pd foil, from the cubic MgPd structure in the case of sample 3, and from the cubic $\mathrm{Mg}_{6} \mathrm{Pd}$ structure in the case of

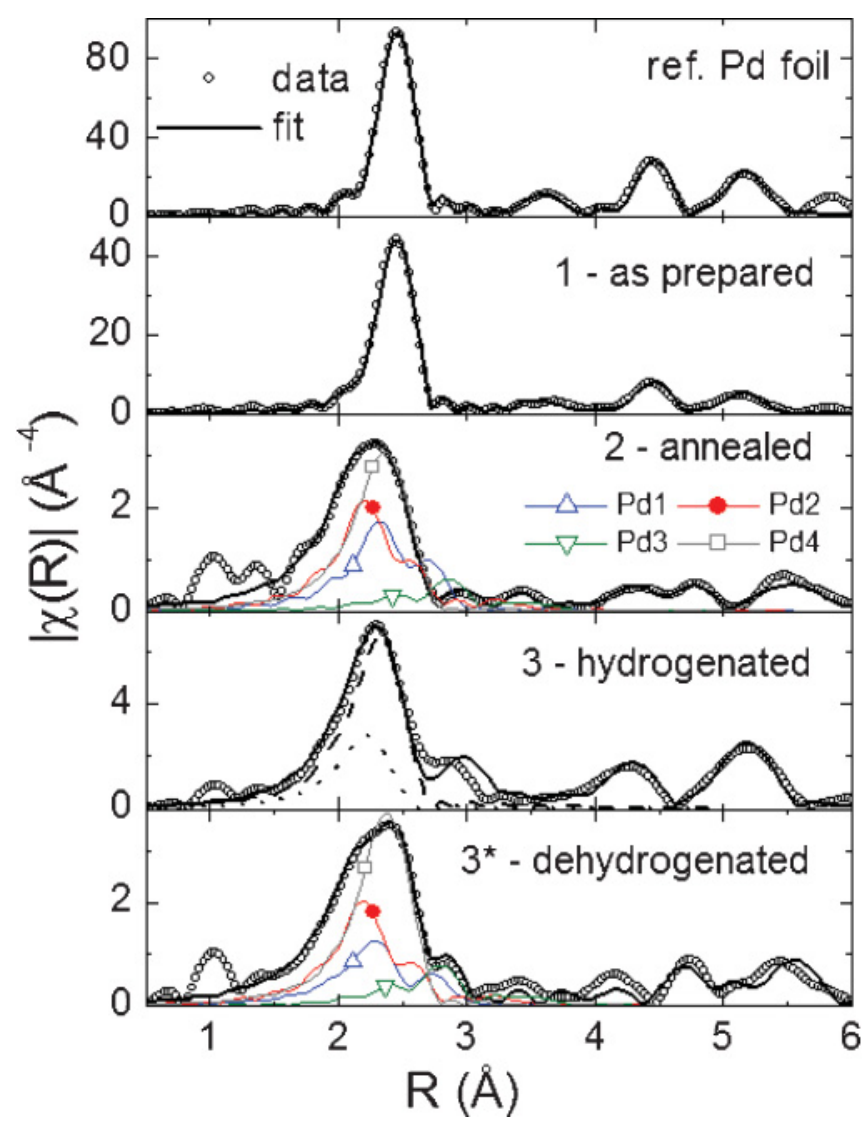

FIG. 5. (Color online) Magnitude of the FT of raw EXAFS spectra (open circles). The continuous lines represent the fit performed with ARTEMIS. In the graphs of sample 2 and $3^{*}$, the first-shell-like contributions from the four different $\mathrm{Pd}$ sites in the $\mathrm{Mg}_{6} \mathrm{Pd}$ structure are displayed as thin solid lines marked by one symbol. Each specific contribution corresponds to the sum of SS paths comprised in the path-length range reported in Table III. In the graph of sample 3, the dashed and dotted lines represent the fit contributions coming from the first shell of $\mathrm{MgPd}$ and from a shell of eight $\mathrm{Mg}$ atoms, with weight coefficients of 0.73 and 0.27 , respectively, as determined from XRD analysis.

samples 2 and $3^{*}$. Contributions from both single scattering (SS) and multiple (MS) paths were taken into account. Since in the $\mathrm{Mg}_{6} \mathrm{Pd}$ structure Pd has four nonequivalent sites, in order to describe the scattering paths used in the fitting we introduce a specific notation; $A m \_n$ indicates the scattering atom the chemical symbol of which is $A$ and which is the $n$th nearest neighbor of the central Pd atom located in site $m$ (for fcc Pd and cubic $\operatorname{MgPd} m$ is always equal to 1). SS paths are identified by a single $A m \_n$ symbol while MS paths are unambiguously identified by a list of more symbols.

For all samples, the fitting parameters were a common shift of the energy origin, variations in the interatomic distances, and Debye-Waller factors $\sigma^{2}$. For the NP samples the $S_{0}^{2}$ amplitude reduction factor was fixed to the value 0.97 , determined from the fit of the reference Pd foil. The results of the fitting procedure, together with the coordination numbers $N$ for all paths, are summarized in Tables II-IV. The interatomic distances are expressed as a deviation $\Delta R$ from the value $R_{\text {cryst }}$ reported in the Inorganic Crystal Structures Database (ICSD). ${ }^{31}$ Coordination numbers were kept fixed to their 
TABLE II. Results of the quantitative analysis of EXAFS spectra for the Pd foil and sample 1. The structural parameters determined from the fit are the path-length deviation with respect to the crystallographic structure, $\Delta R \equiv R-R_{\text {cryst }}$, the Debye-Waller factor $\sigma^{2}$, and, for sample 1 , a parameter $\alpha$ that accounts for the decrease of the coordination numbers $N$ by a common factor $\left(1-\alpha R_{\text {cryst }}\right)$.

\begin{tabular}{|c|c|c|c|c|c|c|c|}
\hline \multirow[b]{2}{*}{ Path } & \multirow[b]{2}{*}{$R_{\text {cryst }}(\AA)$} & \multicolumn{3}{|c|}{ Reference Pd foil } & \multicolumn{3}{|c|}{ Sample 1} \\
\hline & & $\Delta R(\AA)$ & $\sigma^{2}\left(10^{-3} \AA^{2}\right)$ & $N$ & $\Delta R(\AA)$ & $\sigma^{2}\left(10^{-3} \AA^{2}\right)$ & $N$ \\
\hline Pd1_1 & 2.7506 & $\Delta R_{1}=-0.005(2)$ & $2.8(2)$ & 12 & $\Delta R_{1}=-0.007(2)$ & $4.1(2)$ & $8.5(12)$ \\
\hline Pd1_2 & 3.8900 & $\Delta R_{2}=-0.010(9)$ & $4.6(10)$ & 6 & $\Delta R_{2}=-0.014(20)$ & $8(2)$ & $3.5(5)$ \\
\hline Pd1_1 Pd1_1 & 4.1260 & $3 \Delta R_{1} / 2$ & $4(5)$ & 48 & $3 \Delta R_{1} / 2$ & $4(4)$ & $27(4)$ \\
\hline Pd1_2 Pd1_1 & 4.6956 & $\Delta R_{1}+\Delta R_{2} / 2$ & $0.9(14)$ & 48 & $\Delta R_{1}+\Delta R_{2} / 2$ & $4(8)$ & $24(3)$ \\
\hline Pd1_3 & 4.7643 & $\Delta R_{3}=-0.002(12)$ & $4.1(9)$ & 24 & $\Delta R_{3}=0.002(12)$ & $5.6(9)$ & $12(2)$ \\
\hline Pd1_1 Pd1_1 & 5.1328 & $\Delta R_{1}+\Delta R_{3} / 2$ & $4(13)$ & 48 & $\Delta R_{1}+\Delta R_{3} / 2$ & $5(11)$ & $22(3)$ \\
\hline Pd1_3 Pd1_1 & 5.1328 & $\Delta R_{3} / 2+\Delta R_{1}$ & $4(9)$ & 96 & $\Delta R_{3} / 2+\Delta R_{1}$ & $4(6)$ & $43(6)$ \\
\hline Pd1_4 & 5.5013 & $\Delta R_{4}=-0.04(7)$ & $5(2)$ & 12 & $\Delta R_{4}=-0.04(12)$ & $5(4)$ & $4.9(7)$ \\
\hline Pd1_1 Pd1_1 & 5.5013 & $\Delta R_{1}+\Delta R_{4} / 2$ & $1(4)$ & 12 & $\Delta R_{1}+\Delta R_{4} / 2$ & $4(5)$ & $4.9(7)$ \\
\hline Pd1_4 Pd1_1 & 5.5013 & $\Delta R_{1}+\Delta R_{4} / 2$ & $4(3)$ & 24 & $\Delta R_{1}+\Delta R_{4} / 2$ & $5(5)$ & $9.8(14)$ \\
\hline Pd1_1 [+] Pd1_1 & 5.5013 & $2 \Delta R_{1}$ & $4(3)$ & 12 & $2 \Delta R_{1}$ & $5(5)$ & $4.9(7)$ \\
\hline Pd1_1 Pd1_4 Pd1_1 & 5.5013 & $2 \Delta R_{1}$ & $4(3)$ & 12 & $2 \Delta R_{1}$ & $5(5)$ & $4.9(7)$ \\
\hline
\end{tabular}

crystallographic values, except for sample 1 (see Sec. IV A). The variations of the interatomic distances of SS paths were free parameters of the fit, while those of MS paths were bound to the relations listed in Tables II and III. Instead, the Debye-Waller factors were left as independent fit parameters for both SS and MS contributions, since their relation is not obvious to determine. In all cases the number of fitting parameters was smaller than the number of independent points $2\left(R_{\max }-R_{\min }\right)\left(k_{\max }-k_{\min }\right) / \pi$ determined from the FT ranges in $k$ and $R$ space. The fits are reported as the continuous lines in Fig. 5.

\section{In situ XANES}

The modification of the local structure around Pd during the first annealing of as-prepared sample 1 and $\mathrm{H}$ desorption from sample 3 was monitored by in situ XANES measurements in steps of increasing temperature. For each temperature, several spectra were collected under isothermal conditions. The progressive evolution from the XANES spectra of the initial state $\mu_{i}(E)$ toward the final state $\mu_{f}(E)$ is displayed in Fig. 6 for annealing and in Fig. 7 for dehydrogenation. The intermediate spectra were fitted by a linear combination $A_{i} \mu_{i}(E)+A_{f} \mu_{f}(E)$ with coefficients calculated according to the least-square criterion. The agreement between these linear combinations and the data is quite good, as shown by the symbols in Figs. 6 and 7. The decomposition of XANES spectra of multiphase materials into a combination of the XANES spectra of the constituent phases permits to estimate the fraction of absorber atoms in the various phases. ${ }^{32}$ The insets of Figs. 6 and 7 depict the time and temperature history used for the in situ XANES experiments and the parallel increase of $A_{f}$ from 0 to 1 . For the annealing experiment, the coefficient $A_{f}$ tracks the irreversible formation of the $\mathrm{Mg}-\mathrm{Pd} \mathrm{IMC}$ due to alloying at the $\mathrm{Mg} / \mathrm{MgO} / \mathrm{Pd}$ interface, while for the dehydrogenation experiment, $A_{f}$ tracks the reversible transformation between two different $\mathrm{Mg}$-Pd phases. In both cases the final state exhibits a local structure similar to $\mathrm{Mg}_{6} \mathrm{Pd}$.

We observe that significant deviations from the initial fcc Pd structure start during annealing already at $T 2=473 \mathrm{~K}$, where $A_{f} \sim 0.6$ after $\sim 8000 \mathrm{~s}$ isotherm time (Fig. 6). At this

TABLE III. Results of the quantitative analysis of EXAFS spectra for samples 2 and $3^{*}$, based on the cubic $\mathrm{Mg}_{6} \mathrm{Pd}$ structure. The different sites for Pd and associated number of paths, divided into two subgroups of path lengths, are reported. The structural parameters determined from the fit are the path-length deviation $\Delta R \equiv R-R_{\text {cryst }}$ and the Debye-Waller factor $\sigma^{2}$ for each subgroup. Note that the Debye-Waller factors $\sigma^{2}$ of the longer paths are constrained to the same value. Coordination numbers were kept fixed to the crystallographic values.

\begin{tabular}{|c|c|c|c|c|c|c|c|c|}
\hline \multirow[b]{2}{*}{ Site } & \multirow[b]{2}{*}{$\begin{array}{c}\text { Site } \\
\text { multiplicity }\end{array}$} & \multirow[b]{2}{*}{$\begin{array}{c}\text { Site } \\
\text { occupancy }\end{array}$} & \multirow[b]{2}{*}{$\begin{array}{l}\text { Number } \\
\text { of paths }\end{array}$} & \multirow[b]{2}{*}{$\begin{array}{c}\text { Path-length } \\
\text { range }(\AA)\end{array}$} & \multicolumn{2}{|c|}{ Sample 2} & \multicolumn{2}{|c|}{ Sample $3^{*}$} \\
\hline & & & & & $\Delta R(\AA)$ & $\sigma^{2}\left(10^{-3} \AA^{2}\right)$ & $\Delta R(\AA)$ & $\sigma^{2}\left(10^{-3} \AA^{2}\right)$ \\
\hline \multirow[t]{2}{*}{ Pd1 } & 16 & 1 & $4^{\mathrm{a}}$ & $2.78-3.12$ & $-0.02(2)$ & $3(2)$ & $-0.03(4)$ & $6(5)$ \\
\hline & & & 38 & $4.33-6.12$ & $-0.10(3)$ & $10(3)$ & $0.08(2)$ & 7 (1) \\
\hline \multirow[t]{2}{*}{$\mathrm{Pd} 2$} & 16 & 1 & $4^{\mathrm{a}}$ & $2.67-3.62$ & $-0.04(2)$ & $4.4(12)$ & $-0.05(2)$ & $5.0(16)$ \\
\hline & & & 30 & $4.35-6.17$ & $0.05(5)$ & $10(3)$ & $-0.10(3)$ & 7 (1) \\
\hline \multirow[t]{2}{*}{$\mathrm{Pd} 3$} & 16 & 0.49 & $4^{\mathrm{a}}$ & $2.83-3.76$ & $0.11(5)$ & $5(1)$ & $0.04(5)$ & $4.0(16)$ \\
\hline & & & 24 & $4.62-6.19$ & 0.07 (11) & $10(3)$ & $0.04(5)$ & 7 (1) \\
\hline \multirow[t]{2}{*}{$\mathrm{Pd} 4$} & 16 & 1 & $4^{\mathrm{a}}$ & $2.84-2.96$ & $-0.094(14)$ & 4.5 (17) & $-0.098(15)$ & $2.8(16)$ \\
\hline & & & 39 & $4.36-5.90$ & $0.09(3)$ & $10(3)$ & $0.06(1)$ & 7 (1) \\
\hline
\end{tabular}

${ }^{\mathrm{a}}$ All SS paths with Mg as scattering atom. 
TABLE IV. Results of the quantitative analysis of EXAFS spectra for sample 3, based on the cubic MgPd structure. The structural parameters determined from the fit are the path-length deviation with respect to the crystallographic value $\Delta R \equiv R-R_{\text {cryst }}$ and the Debye-Waller factor $\sigma^{2}$, while the coordination numbers $N$ were kept fixed. The last row is a coordination shell of $\mathrm{Mg}$ atoms, with distance $R$ and Debye-Waller free fit parameters, which describes the presence of $\mathrm{Mg}_{3} \mathrm{Pd}$ and $\mathrm{Mg}_{5} \mathrm{Pd}_{2}$ phases.

\begin{tabular}{|c|c|c|c|c|}
\hline Path & $R_{\text {cryst }}(\AA)$ & $\Delta R(\AA)$ & $\sigma^{2}\left(10^{-3} \AA^{2}\right)$ & $N$ \\
\hline Mg1_1 & 2.7020 & $\Delta R_{1}=0.06(1)$ & $6.6(17)$ & 8 \\
\hline Pd1_1 & 3.1200 & $\Delta R_{2}=-0.015(18)$ & $16(2)$ & 6 \\
\hline $\mathrm{Pd} 1 \_2$ & 4.4123 & $\Delta R_{3}=0.071(16)$ & $13(2)$ & 12 \\
\hline Mg1_2 & 5.1739 & $\Delta R_{4}=0.09(5)$ & $19(8)$ & 24 \\
\hline Pd1_3 & 5.4040 & $\Delta R_{5}=0.09(7)$ & $9(1)$ & 8 \\
\hline Pd1_3 Mg1_1 & 5.4040 & $\Delta R_{5} / 2+\Delta R_{1}$ & $6(4)$ & 16 \\
\hline Mg1_1 Pd1_3 Mg1_1 & 5.4040 & $2 \Delta R_{1}$ & $6(4)$ & 8 \\
\hline \multicolumn{5}{|c|}{$\begin{array}{l}\text { First-shell contribution (weight } 0.27 \text { from XRD) } \\
\text { added to represent } \operatorname{Mg}_{x} \operatorname{Pd}_{y} \text { phases }\end{array}$} \\
\hline Mg_1 & $R=2.65$ (fitted) & $7(4)$ & 8 & \\
\hline
\end{tabular}

stage we can therefore expect the existence of a $\mathrm{Mg}_{\mathrm{x}} \mathrm{Pd}_{\mathrm{y}}$ layer which separates the surface $\mathrm{Pd}$ from $\mathrm{Mg} / \mathrm{MgO}$. After the final isotherm at $T 5=553 \mathrm{~K}$ the Pd local structure is the same as for the ex situ annealed sample 2, meaning that the formation of the IMC is completed. This aspect was checked by running a complete EXAFS measurement at $80 \mathrm{~K}$ after the experiment (not shown).

In correspondence with each temperature increment, the rate of the transformations, defined as $\kappa(t ; T) \equiv\left(\partial A_{f} / \partial t\right)_{T}$, clearly exhibits a stepwise increase. In Fig. 7, we notice that in the temperature range $T 1<T<T 4$, the isothermal transformation rate is almost time independent, i.e., $\kappa(t ; T) \approx$ $\kappa(T)$. Assuming an Arrhenius-like temperature dependence for $\kappa(T)$, we can thus estimate an apparent activation energy of 0.6 (1) $\mathrm{eV}$ for the transition of the Pd local structure from $\mathrm{MgPd}$ to $\mathrm{Mg}_{6} \mathrm{Pd}$ during dehydrogenation. This value is close

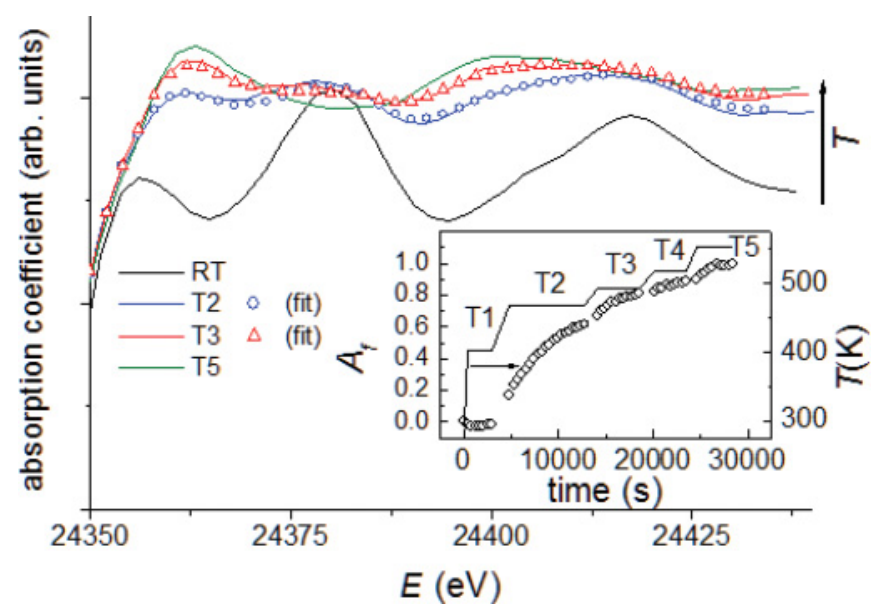

FIG. 6. (Color online) Modification of the Pd local structure during the first temperature increase, from the initial as-prepared state to the final annealed state, monitored by in situ XANES measurements at steps of increasing temperature. For the intermediate temperatures $T 2, T 3$, the symbols represent the linear combinations of the initial and final spectra with coefficients $A_{i}$ and $A_{f}$, which best fit the data. The inset displays the time-temperature profile used for the experiment and the relative evolution of the coefficient $A_{f}$. to the one reported for $\mathrm{H}$ desorption in nanocrystalline $\mathrm{MgH}_{2}$ catalyzed by $T M \mathrm{~s} .{ }^{33}$ Differently, for the formation of $\mathrm{Mg}-\mathrm{Pd}$ IMCs observed during annealing, a reliable estimation of the activation energy is hindered by the marked time dependence $\kappa(t ; T)$ likely due to the slowing down of the transformation as equilibrium is approached.

\section{DISCUSSION}

The experimental data presented so far demonstrate that the exposure of $\mathrm{Mg}-\mathrm{Pd}$ interfaces to elevated temperatures and to interaction with hydrogen induces both reversible and irreversible transformations of their local structure. On these grounds we stress that the usually adopted elementary picture in which Pd acts solely as a catalyst should be taken with caution, since it will be valid only as long as the temperature

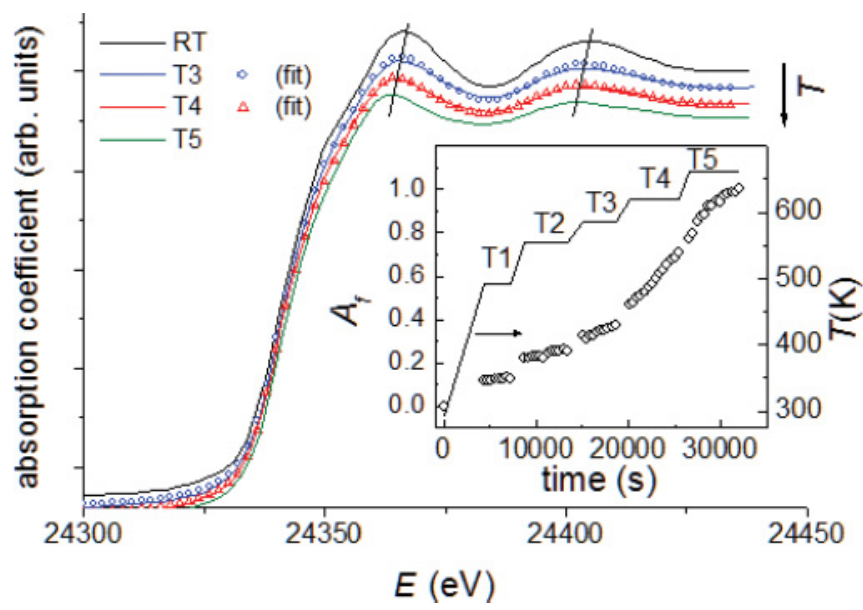

FIG. 7. (Color online) Modification of the Pd local structure during hydrogen desorption, from the initial hydrogenated state to the final dehydrogenated state, monitored by in situ XANES measurements at steps of increasing temperature. For the intermediate temperatures $T 3, T 4$, the symbols represent the linear combinations of the initial and final spectra with coefficients $A_{i}$ and $A_{f}$, which best fit the data. The inset displays the time-temperature profile used for the experiment and the relative evolution of the coefficient $A_{f}$. 
is low. In the following, we discuss the local structure of the various equilibrium states, the mechanisms involved in the transformations between them, and the relevance to the thermodynamics of hydride phases.

\section{A. fec Pd clusters on $\mathrm{MgO}$}

The fit of the Pd foil is of excellent quality and the deviations of the interatomic distances are very small, as expected for state of the art EXAFS analysis including MS contributions. In the fit of sample 1, for which, due to size effects, a reduction of the coordination numbers with respect to the $\mathrm{Pd}$ foil is expected (and confirmed by the strongly reduced amplitude of the EXAFS signal) a specific approach was adopted. Since the decrease of the coordination number $N$ due to finite size is given by a factor $\left(1-\alpha R_{\text {cryst }}\right),{ }^{34}$ we inserted this equation in the fitting model with $\alpha$ as a free parameter. For isolated spherical clusters of diameter $D \gg R_{\text {cryst }}$, it is straightforward to derive that $\alpha=3 / D$. Using this relation and the fit result for $\alpha$, a cluster diameter of 3.0 (4) $\mathrm{nm}$ is estimated, in agreement with TEM observations ${ }^{8}$ and XRD line broadening analysis, indicating that the Pd clusters in the as-prepared state are mostly constituted by one single crystallite free of grain boundaries or twins. The higher Debye-Waller factors in sample 1 with respect to the Pd foil, particularly evident for the first two coordination shells (Table II), can be explained by the larger static and thermal disorder experienced by the atoms in close proximity of the cluster's surface.

From inspection of Table II it appears that the interatomic distances determined for sample 1 are the same, within the errors, as those of the reference Pd foil. This might seem surprising at first glance since a contraction of distances has generally been found for small metallic clusters. ${ }^{35,36}$ In a macroscopic liquid drop model this is due to a surface tension effect yielding a contraction which is inversely proportional to the cluster size. Analysis of the literature shows that reports on Pd clusters have apparently been contradictory. In fact, distances essentially equal to those of bulk Pd have been found using XAFS for clusters stabilized by organic ligands, ${ }^{37,38}$ clusters supported in $\mathrm{SiO}_{2},{ }^{39}$ and embedded in mesoporous carbon. ${ }^{40}$ On the other hand, a clear contraction of the lattice parameter has been detected for Pd clusters in a plasma polymer film by electron diffraction. ${ }^{41}$ Krüger et al. ${ }^{42}$ having noted the contradictory situation, performed $a b$ initio density functional simulations and found that Pd clusters share the same behavior as other metallic clusters; they proposed that interaction with the support and environment is responsible for the lack of contraction in many cases. The situation might be similar to that found for $\mathrm{Ag}$ clusters supported on $\mathrm{MgO}(001)$, the structure of which was carefully studied by surface XAFS by Lagarde et $a l .{ }^{43}$ These authors followed the change in nearest-neighbor distance as a function of coverage and found that two regimes could be identified. At very low cluster sizes the surface tension effect dominates and the distance does contract as an inverse function of size (as expected) while above a critical size $(\sim 2 \mathrm{~nm})$ interactions with the substrate (presumably bonding to oxygen atoms, which are found at $2.98 \AA$ in the $\mathrm{MgO}$ structure) cause a rather abrupt increase, followed by a convergence to the bulk value. It is very likely that in the present case a similar situation occurs, since the size of the Pd clusters is intermediate $(\sim 3 \mathrm{~nm})$; we thus attribute the bulklike value of the Pd interatomic distances in sample 1 to the interaction with the $\mathrm{MgO}$ environment. The fact that we do not detect a Pd-O signal in the XAFS spectrum is not unreasonable, in view of the low backscattering amplitude of $\mathrm{O}$ atoms, the high maximum wave number used in the analysis, and the high structural disorder expected for a $\mathrm{Pd}-\mathrm{O}$ signal in the present case. The occurrence of $\mathrm{Pd}-\mathrm{O}$ bonding at the very surface layers of the Pd clusters is suggested by XPS results on the Pd $3 d$ binding energy, as reported in Sec. III B. We conclude that the absence of a contraction in the interatomic distances for sample 1 can be rationalized in the framework of the existing knowledge on the structure of small Pd clusters.

\section{B. Mg-rich IMC}

The thermodynamic driving force for the irreversible transformation from sample 1 to sample 2 is the formation enthalpy $\Delta_{\mathrm{f}} H^{\mathrm{Mg}_{6} \mathrm{Pd}}$ of the $\mathrm{Mg}_{6} \mathrm{Pd}$ IMC, which is the expected equilibrium phase in the $\mathrm{Mg}$-rich region of the binary $\mathrm{Mg}-\mathrm{Pd}$ phase diagram. ${ }^{44}$ Using the semiempirical Miedema model, Fernandez et al. have calculated $\Delta_{\mathrm{f}} H^{\mathrm{Mg}_{6} \mathrm{Pd}}=-21.8 \mathrm{~kJ} / \mathrm{mol}$ at $0 \mathrm{~K}$. On account of the extremely high stability of $\mathrm{MgO}$ $\left(\Delta_{\mathrm{f}} H^{\mathrm{MgO}}=-601 \mathrm{~kJ} / \mathrm{mol}\right)$, the only $\mathrm{Mg}$ atoms available for the reaction with $\mathrm{Pd}$ are those from the metallic NP core. Therefore, the formation of $\mathrm{Mg}_{6} \mathrm{Pd}$ requires first the diffusion through the $\mathrm{MgO}$ shell, in order to bring $\mathrm{Mg}$ and $\mathrm{Pd}$ atoms in proximity, followed by interdiffusion between $\mathrm{Mg}$ and $\mathrm{Pd}$ to attain the final $\mathrm{Mg}_{6} \mathrm{Pd}$ local structure. According to the in situ annealing XANES experiment (Fig. 6), Mg-Pd alloying occurs already at $473 \mathrm{~K}$. At this temperature, the diffusion of $\mathrm{Mg}^{2+}$ cations through a 5-nm-thick, defect-free $\mathrm{MgO}$ crystal would be negligible on the time scale of the experiments. ${ }^{45}$ However, the $\mathrm{MgO}$ layer is nanocrystalline and therefore has a high density of grain boundaries, where diffusion is faster by $2-3$ orders of magnitude with respect to the bulk due to the less densely-packed structure. ${ }^{46}$ Such situation allows for appreciable diffusion of $\mathrm{Mg}^{2+}$ cations and possibly of Pd atoms, although Pd mobility is expected to be lower because of the larger atomic radius. The large increase in crystallite size from $D_{\mathrm{Pd}}=4 \mathrm{~nm}$ to $D_{\mathrm{Mg} 6 \mathrm{Pd}}=70 \mathrm{~nm}$ points to a significant spatial rearrangement of $\mathrm{Pd}$ atoms. It is reasonable to expect that the formation of $\mathrm{Mg}-\mathrm{Pd}$ IMCs would take place at even lower temperatures in $\mathrm{Mg} / \mathrm{Pd}$ without an intermediate $\mathrm{MgO}$ layer. Depending on the time and temperature history, a complete solid-state reaction may occur or only a partial intermixing region separating the two metals may develop. In the present case the equilibrium IMC is obtained, suggesting that the $\mathrm{MgO}$ diffusion barrier is completely overcome. Since the $\mathrm{MgO}$ content does not increase further during $\mathrm{H}$-sorption cycles, ${ }^{13}$ and taking into account that the formation of a $\mathrm{Mg}-\mathrm{Pd}-\mathrm{O}$ ternary phase is not expected, it is reasonable to assume that the subsequent transformations involving $\mathrm{Mg}-\mathrm{Pd}$ phases are not affected by $\mathrm{MgO}$. This argument is also supported by the fact that the transformation paths are similar to the ones observed in bulk, oxygen-free $\mathrm{Mg}_{6} \mathrm{Pd}$ (see Sec. IV C for discussion).

The local structure of $\mathrm{Pd}$ in the $\mathrm{Mg}_{6} \mathrm{Pd} \mathrm{IMC}$ is rather complex and consequently the analysis of samples 2 and $3^{*}$ poses some particular challenges. Pd has four independent sites 
in the $\mathrm{Mg}_{6} \mathrm{Pd}$ structure, each characterized by a rather broad distribution of interatomic distances. This is a classical case in which EXAFS analysis cannot be performed in the "standard" fashion in which the fine-structure signal is fitted with a limited number of SS and/or MS contributions originating from well-defined coordination shells, assuming a Gaussian radial distribution function (RDF). For the present case the number of contributions to be considered would be so high that the number of fitting parameters would exceed the number of independent data points. Another approach might be to "blindly" fit each peak in the FT, assuming only prior knowledge on the composition of the corresponding coordination shell, in order to extract average local structural parameters. It is known that the determination of coordination numbers is often troublesome in this case. ${ }^{47}$ In the case of disordered solids and liquids the use of higher-order cumulants to describe the $\mathrm{RDF}^{48}$ and the use of analytic expressions for skewed distributions ${ }^{49}$ have often been successfully used. Finally, a histogram approach based on binning the RDF obtained from $a b$ initio structural simulations with a $0.02 \AA$ step has recently successfully been used. ${ }^{50}$ In the present case, we have found that the approach which provided good fits of the experimental data while maintaining a good physical insight in the local structure and correspondence to the crystallographic structure of $\mathrm{Mg}_{6} \mathrm{Pd}$ consisted in grouping the RDF in a small number of separate contributions, each representing the average signal from similar atomic configurations; a Gaussian RDF was assumed for each average contribution.

Inspection of the crystallographic structure of $\mathrm{Mg}_{6} \mathrm{Pd}$ shows that for each Pd site, the four shortest paths are SS paths with $\mathrm{Mg}$ as the scattering atom which contribute to the main peak of the FT in the range 1.6-3.0 $\AA$. These SS paths are akin to first-shell contributions, because their interatomic distances are similar. Therefore, we used one single value of $\Delta R$ and $\sigma^{2}$ as fitting parameters for the four SS paths associated with the same site, thus eight parameters for the first shell. The other contributions are found at higher interatomic distances and include both SS and MS paths with quite low amplitude. To represent them, we use four different $\Delta R$ values, again one for each $\mathrm{Pd}$ site, and only one $\sigma^{2}$ common to all $\mathrm{Pd}$ sites. This makes a total of eight $\Delta R$ and five $\sigma^{2}$ fitting parameters. Table III reports, for each Pd site, the total number of paths, divided into two subgroups with the relative range of interatomic distances, and the fit results for $\Delta R$ and $\sigma^{2}$. The specific first-shell-like contributions from the four $\mathrm{Pd}$ sites, obtained from the sum of the corresponding SS paths, are displayed as thin solid lines in Fig. 5. The local structure parameters obtained for samples 2 and $3^{*}$ are very similar and do not show significant deviations from the crystallography values. As concerns the first-shell-like contributions, the differences between samples 2 and $3^{*}$ are smaller than the associated uncertainties. The first-shell interatomic distance seems to exhibit a small expansion for site Pd3 and a small contraction for site Pd4 (Table III), although the uncertainties due to strong correlations between contributions from different sites do not allow to draw a definite conclusion. By inspecting also the other $\Delta R$ values reported in Table III, no evidence is found in favor of a net average expansion of the interatomic distance, which is compatible with the idea that $\mathrm{H}$ is not in solid solution in these samples. In general, both the fit results of Table III and the FT displayed in Fig. 5, where sample 2 exhibits more damped features, suggest a higher structural disorder in sample 2 which affects particularly the longer interatomic distances. This finding might be explained by a reduction of local strains during the high-temperature $\mathrm{H}$ desorption (Fig. 7) that leads to sample 3*.

\section{Hydrogenated $\mathrm{MgPdH}_{\delta}$ structure}

When the $\mathrm{Mg}_{6} \mathrm{Pd}$ IMC is exposed to elevated hydrogen pressure, a different thermodynamic driving force, namely, the free energy of the transformation $\mathrm{Mg}+\mathrm{H}_{2} \rightarrow \mathrm{MgH}_{2}$, comes into play. Its competition with the driving force for the formation of $\mathrm{Mg}-\mathrm{Pd}$ intermetallics modifies the equilibrium phase expected at a particular $\mathrm{Mg} / \mathrm{Pd}$ atomic ratio, resulting in a different Pd local structure. Looking solely at the $\mathrm{Mg}-\mathrm{Pd}$ compound phases, the following reversible transformation can be envisaged upon $\mathrm{H}$ sorption:

$$
\mathrm{Mg}_{6} \mathrm{Pd}+5 \mathrm{H}_{2} \leftrightarrow \mathrm{MgPd}+5 \mathrm{MgH}_{2} .
$$

The occurrence of transformation (1) was demonstrated recently by neutron diffraction on quenched bulk $\mathrm{Mg}_{6} \mathrm{Pd}$ samples ${ }^{51}$ and also by our investigation of Mg-Pd NPs using in situ XRD with synchrotron radiation. ${ }^{13}$ These studies also showed that transformation (1) can be decomposed in at least two steps at intermediate hydrogen pressures. At these steps, other Mg-Pd phases whose Pd content lies in between $\mathrm{Mg}_{6} \mathrm{Pd}$ and $\mathrm{MgPd}$ appear, namely, $\mathrm{Mg}_{3.65} \mathrm{Pd}, \mathrm{Mg}_{3} \mathrm{Pd}$, and $\mathrm{Mg}_{5} \mathrm{Pd}_{2}$. The plateau pressure at $573 \mathrm{~K}$ of the final transformation step leading to $\mathrm{MgPd}$ was determined as $3 \mathrm{MPa}$ in absorption and 1.5 $\mathrm{MPa}$ in desorption, ${ }^{51}$ significantly higher than $\sim 0.1 \mathrm{MPa}$ for $\mathrm{MgH}_{2}$ formation from the elements.

In attempting to fit the EXAFS signal of sample 3 with the SS and MS contributions expected for the MgPd structure only, some difficulties were encountered. In fact, the FT peak corresponding to the first coordination shell, constituted by eight $\mathrm{Mg}$ atoms at $R \sim 2.7 \AA$, is significantly higher in the experimental data than in the fit. Such a discrepancy is, however, not surprising, since $\mathrm{XRD}$ shows that residual traces of $\mathrm{Mg}_{5} \mathrm{Pd}_{2}$ and $\mathrm{Mg}_{3} \mathrm{Pd}$ are present in the sample. This is probably due to kinetics limitations in the development of transformation (1). More quantitatively, from Table I we derive that the relative fraction of $\mathrm{Pd}$ atoms pertaining to the $\mathrm{MgPd}$ phase is equal to 0.73 . The FT of both $\mathrm{Mg}_{5} \mathrm{Pd}_{2}$ and $\mathrm{Mg}_{3} \mathrm{Pd}$, which exhibit a broad distribution of interatomic distances similar to $\mathrm{Mg}_{6} \mathrm{Pd}$, is characterized by a main peak at $R \sim 2.7 \AA$ (this value is actually the typical Mg-Pd first neighbor distance of all the IMCs examined in this study). Therefore, in order to account for the presence of $\mathrm{Mg}_{x} \mathrm{Pd}_{y}$ phases in the quantitative EXAFS analysis of sample 3, without turning to an excessively complicated model with too many parameters, we made the following approximation: The $\mathrm{Mg}_{x} \mathrm{Pd}_{y}$ phases are represented by introducing a coordination shell with Gaussian RDF, composed of eight $\mathrm{Mg}$ atoms, and with a relative weight fixed to $1-0.73=0.27$. The interatomic distance (initial guess value $2.7 \AA$ ) and Debye-Waller factor of this shell become two additional free parameters of the fit. With this simple approximation a good quality fit is obtained, as reported in Fig. 5, where the two contributions to the first FT peak are also displayed separately. The discrepancy 
remaining between fit and experiment in the region $R \sim 3 \AA$, corresponding to the $\mathrm{Pd} 1 \_1$ path, is probably due to the fact that our approximation does not take fully into account the details of $\operatorname{Mg}_{x} \mathrm{Pd}_{y}$ signals. At higher $R>3.5 \AA$, where the signals from $\operatorname{Mg}_{x} \mathrm{Pd}_{y}$ are weaker and tend to phase out each other, the contributions from the Pd1_2 and Pd1_3 paths of the $\mathrm{MgPd}$ structure are reproduced very well.

The fit results (Table IV) point at an increased interatomic distance with respect to the crystallographic value (the only exception being the Pd1_1 path, whose reliability suffers from the above approximation). The relative expansion is $\sim 2.2 \%$ for the Mg1_1 path and $\sim 1.6 \%$ for the other paths. In agreement with this result, XRD of sample 3 yields a $\mathrm{MgPd}$ lattice parameter of 3.16 (1) $\AA$, which is larger by $\sim 1.3 \%$ with respect to the $3.12-\AA$ value that corresponds to the Pd1_1 path length listed in the ICSD. An expanded lattice parameter of 3.1570(3) $\AA$ was observed also in bulk MgPd after hydrogenation at $573 \mathrm{~K}$ under $4-\mathrm{MPa}$ pressure. ${ }^{51}$ These findings support the idea that $\mathrm{H}$ enters in solid solution in the MgPd phase. Taking the $1.6 \%$ value for the average lattice expansion, the unit-cell volume would be increased by $1.2 \AA^{3}$ with respect to the literature value of $30.37 \AA^{3}$. Since it is generally accepted that the unit cell of a metal hydride expands between 2 and $3 \AA^{3}$ per $\mathrm{H}$ atom absorbed, ${ }^{52}$ it can be estimated in the present case that $0.4-0.6 \mathrm{H}$ atoms are in solid solution in the $\mathrm{MgPd}$ unit cell. In the light of these results, transformation (1) should be rewritten more precisely as

$$
\mathrm{Mg}_{6} \mathrm{Pd}+(5+\delta / 2) \mathrm{H}_{2} \leftrightarrow \mathrm{MgPdH}_{\delta}+5 \mathrm{MgH}_{2}
$$

with $\delta$ in the range $0.4-0.6$. The lattice strain associated to the presence of $\mathrm{H}$ in solid solution is one possible cause of the quite high Debye-Waller factors determined for the MgPd phase (Table IV). Another cause lies in the strains at the $\mathrm{MgPd} / \mathrm{MgH}_{2}$ phase boundaries that become relevant for MgPd nanocrystals immersed in a $\mathrm{MgH}_{2}$ matrix.

The thermodynamics and kinetics issues related to transformation (2) deserve further discussion. The Mg-Pd binary phase diagram is rather complex and comprises several intermetallic phases, ${ }^{44}$ a situation that occurs in many other binary systems relevant for $\mathrm{H}$ storage, such as $\mathrm{La}-\mathrm{Ni}, \mathrm{Fe}-\mathrm{Ti}, \mathrm{Ni}-\mathrm{Zr}, \mathrm{Mg}-\mathrm{Cu}$, and $\mathrm{Mg}-\mathrm{Ni}$. Hydride formation at a specific equilibrium pressure $P_{\text {eq }}$ results from a balance between the enthalpy and entropy terms of the free energy, the second being very close to the loss of the entropy of the gas. The enthalpy-entropy balance directly leads to the celebrated Van't Hoff equation $\ln \left(P_{\text {eq }} / P_{0}\right)=\left(\Delta_{\mathrm{f}} H^{\text {hyd }} / T-\Delta_{\mathrm{f}} S_{0}^{\text {hyd }}\right) / R_{\text {gas }}$, where $\Delta_{\mathrm{f}} S_{0}^{\text {hyd }}$ is the entropy change when the transformation occurs at gas pressure $P_{0}$, and $R_{\text {gas }}$ is the gas constant.

The existence of several binary phases introduces a complex enthalpy landscape for the metal-hydride transformation and as a consequence, different equilibrium pressures may arise. This situation contrasts with the case of a simple elemental hydride where only one single equilibrium pressure exists. For the hydrogenation of $\mathrm{Mg}_{6} \mathrm{Pd}$, Fernandez et al. have calculated that $\Delta_{\mathrm{f}} H^{\text {hyd }}$ increases with increasing $\mathrm{Pd}$ content of the final IMC, from $\Delta_{\mathrm{f}} H^{\text {hyd }}=-75.3 \mathrm{~kJ} / \mathrm{mol} \mathrm{H}_{2}$ for $\mathrm{Mg}_{3} \mathrm{Pd}$ to $\Delta_{\mathrm{f}} H^{\text {hyd }}=-69.1 \mathrm{~kJ} / \mathrm{mol} \mathrm{H}_{2}$ for $\mathrm{MgPd}{ }^{53}$ This corresponds to an increase of $P_{\text {eq }}(573 \mathrm{~K})$ from 0.14 to $0.58 \mathrm{MPa}$. (a)

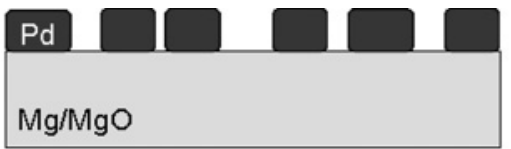

(b)
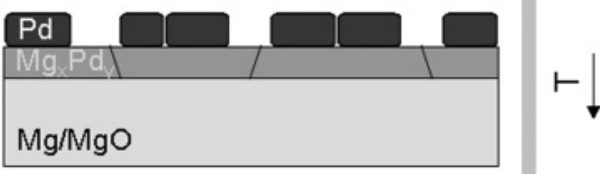

(c)

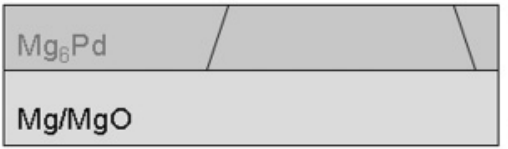

(d)

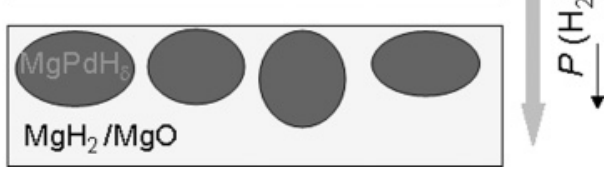

FIG. 8. Schematic evolution of the Mg-Pd interface in response to annealing and $\mathrm{H}$ sorption. (a) Initial state with fcc Pd clusters. (b) An IMC starts to develop upon annealing. (c) The formation of the equilibrium Mg-rich IMC with large crystallites and the disappearance of pure fcc $\mathrm{Pd}$ are completed. (d) $\mathrm{H}$ absorption induces the formation of the Pd-rich $\mathrm{IMC} \mathrm{MgPdH}_{\delta}$, with fine crystallites and $\mathrm{H}$ in solid solution. The transition from (a) to (c) is irreversible, while the one from (c) to (d) can be fully reversed by controlling the $\mathrm{H}_{2}$ pressure.

As for the kinetics issue, it is clear that transformations (1)-(2) require solid-state diffusion of $\mathrm{Mg}$ and $\mathrm{Pd}$. The smaller crystallite size of $\mathrm{MgPd}(12 \mathrm{~nm})$ with respect to $\mathrm{Mg}_{6} \mathrm{Pd}$ $(70 \mathrm{~nm})$ revealed by XRD line broadening analysis indicates that upon $\mathrm{H}$ absorption the $\mathrm{Mg}$-rich initial state decomposes into finer grains of the equiatomic $\mathrm{MgPd}$ phase separated by $\mathrm{MgH}_{2}$. This final microstructure, whose development minimizes the solid-state diffusion length of the involved atomic species, resembles qualitatively the precipitation of a solute. In fact, the Pd-Pd nearest-neighbor distance decreases from the typical values of 4.67-5.67 $\AA$ (depending on the lattice site) of the dehydrogenated samples 2 and $3^{*}$ down to $3.12 \AA$ for the hydrogenated sample 3 (path Pd1_1, Table IV). The reverse rearrangement shall occur upon hydrogen release, i.e., the average $\mathrm{Pd}-\mathrm{Pd}$ distance increases and coarser grains of the Mg-rich phase develop. The apparent activation energy of this diffusion-limited process can be estimated as $0.6 \mathrm{eV}$ according to the in situ XANES experiment. The feeble Pd $3 d$ XPS signal observed in sample 3 before $\mathrm{Ar}^{+}$sputtering is likely due to surface segregation with $\mathrm{Mg}$ enrichment. This effect is commonly encountered in many IMCs, including $\mathrm{Mg}-\mathrm{Ni}, \mathrm{Mg}-\mathrm{Cu}$, and $\mathrm{Mg}-\mathrm{In}$, and is explained by interaction with adsorbed gases or a difference in surface energy of the alloying elements. ${ }^{23}$ A significant increase of the $\mathrm{Pd} 3 d$ signal after $\mathrm{Ar}^{+}$sputtering was reported for bulk $\mathrm{Mg}_{6} \mathrm{Pd}$ as well. ${ }^{23}$

\section{CONCLUSIONS}

The local structure at the $\mathrm{Mg} / \mathrm{MgO} / \mathrm{Pd}$ interface in $\mathrm{Pd}$ decorated $\mathrm{Mg} / \mathrm{MgO}$ core-shell NPs was investigated by a combination of different $\mathrm{X}$-ray spectroscopy techniques with the support of long-range structure information from XRD, 
allowing to map precisely its evolution in response to annealing and $\mathrm{H}$ sorption. The irreversible formation of IMCs which takes place at relatively low annealing temperatures, driven by the negative enthalpy of mixing, profoundly modifies the thermodynamics of hydride formation of the binary nanophase material. In fact, besides affecting the solid-state $\mathrm{H}$-storage capacity, the possible presence of different $\mathrm{Mg}-\mathrm{Pd}$ intermetallic phases introduces a complex enthalpy landscape with various equilibrium pressures for the metal-hydride reversible transition. The irreversible (annealing-induced) and reversible $\left(\mathrm{H}_{2}\right.$ pressure-induced) changes in the local structure of these phases, as derived from the present investigation, are summarized in Fig. 8, which sketches the picture expected for binary systems of miscible elements with different hydride formation enthalpies. The IMC irreversibly formed upon annealing $\left[\mathrm{Mg}_{6} \mathrm{Pd}\right.$, Fig. 8(c)], reversibly transforms upon $\mathrm{H}$ sorption into the hydride of the element with more negative
$\Delta_{\mathrm{f}} H^{\text {hyd }}$ mixed with an IMC richer in the element with less negative $\Delta_{\mathrm{f}} H^{\text {hyd }}$. The final IMC possibly includes $\mathrm{H}$ in a solid solution $\left[\mathrm{MgH}_{2} / \mathrm{MgPdH}_{\delta}\right.$ mixture in Fig. 8(d)]. This disproportionation process, which resembles qualitatively the precipitation of a solute, requires not only $\mathrm{H}$ diffusion but also interdiffusion of the two metals. Therefore, both the IMC formation and the reversible disproportionation may be kinetically limited if the temperature is low, as sketched in Fig. 8(b), where the composition of the separation layer between the two metals does not necessarily coincide with the equilibrium IMC foreseen by the binary phase diagram. These phenomena clearly represent an important step in understanding the physics of hydrogen in multiphase nanomaterials, which are synthesized and studied worldwide from the viewpoint of basic science as well as for many different applications, including sensors, smart optical devices and energy storage.
${ }^{1}$ T. Graham, Philos. Trans. R. Soc. (London) 156, 415 (1866).

${ }^{2}$ F. A. Lewis, The Palladium Hydrogen System (Academic, New York, 1967).

${ }^{3}$ K. H. J. Buschow, P. C. P. Bouten, and A. R. Miedema, Rep. Prog. Phys. 45, 937 (1982).

${ }^{4}$ A. Baldi, M. Gonzalez-Silveira, V. Palmisano, B. Dam, and R. Griessen, Phys. Rev. Lett. 102, 226102 (2009).

${ }^{5}$ A. Baldi, V. Palmisano, M. Gonzalez-Silveira, Y. Pivak, M. Slaman, H. Schreuders, B. Dam, and R. Griessen, Appl. Phys. Lett. 95, 071903 (2009).

${ }^{6}$ Hydrogen in Metals, edited by G. Alefeld and J. Völkl (Springer, Berlin, 1978), Vols. I-III.

${ }^{7}$ K. Higuchia, K. Yamamoto, H. Kajioka, K. Toiyama, M. Honda, S. Orimo, and H. Fujii, J. Alloys Compd. 330-332, 526 (2002).

${ }^{8}$ E. Callini, L. Pasquini, E. Piscopiello, A. Montone, M. Vittori Antisari, and E. Bonetti, Appl. Phys. Lett. 94, 221905 (2009).

${ }^{9}$ F. Tang, T. Parker, H.-F. Li, G.-C. Wang, and T.-M. Lu, Nanotechnology 19, 465706 (2008).

${ }^{10}$ A. Pundt and R. Kircheim, Annu. Rev. Mater. Res. 36, 555 (2006).

${ }^{11}$ C. Langhammer, V. P. Zhdanov, I. Zorić, and B. Kasemo, Phys. Rev. Lett. 104, 135502 (2010).

${ }^{12}$ M. Di Vece, D. Grandjean, M. J. Van Bael, C. P. Romero, X. Wang, S. Decoster, A. Vantomme, and P. Lievens, Phys. Rev. Lett. 100, 236105 (2008).

${ }^{13}$ E. Callini, L. Pasquini, L. H. Rude, T. K. Nielsen, T. R. Jensen, and E. Bonetti, J. Appl. Phys. 108, 073513 (2010).

${ }^{14}$ S. X. Tao, P. H. L. Notten, R. A. van Santen, and A. P. J. Jansen, Phys. Rev. B 82, 125448 (2010).

${ }^{15}$ X. Tan, C. T. Harrower, B. S. Amirkhiz, and D. Mitlin, Int. J. Hydrogen Energy 34, 7741 (2009).

${ }^{16}$ J. L. Slack, J. C. W. Locke, S. W. Song, J. Ona, and T. J. Richardson, Sol. Energy Mater. Sol. Cells 90, 485 (2006).

${ }^{17}$ L. Lutterotti, Nucl. Instrum. Methods Phys. Res. B 268, 334 (2010).

${ }^{18}$ S. Tougaard, Surf. Sci. 216, 343 (1989).

${ }^{19}$ F. D'Acapito et al., ESRF Newsl. 30, 42 (1998).

${ }^{20}$ S. Pascarelli, F. Boscherini, F. D'Acapito, J. Hrdy, C. Meneghini, and S. Mobilio, J. Synchrotron Rad. 3, 147 (1996).
${ }^{21}$ B. Ravel and M. Newville, J. Synchrotron Rad. 12, 537 (2005).

${ }^{22}$ A. L. Ankudinov, B. Ravel, J. J. Rehr, and S. D. Conradson, Phys. Rev. B 58, 7565 (1998).

${ }^{23}$ C. Zlotea and Y. Andersson, Acta Mater. 54, 5559 (2006).

${ }^{24}$ K. S. Kim, A. F. Gossmann, and N. Winograd, Anal. Chem. 46, 197 (1974).

${ }^{25}$ O. Friedrichs, J.C. Sánchez-López, C. López-Cartes, M. Dornheim, T. Klassen, R. Bormann, and A. Fernández, J. Alloys Compd. 434435, 721 (2007).

${ }^{26}$ H. W. Schnopper, Phys. Rev. B 131, 2558 (1963).

${ }^{27}$ A. Filipponi, E. Bernieri, and S. Mobilio, Phys. Rev. B 38, 3298 (1988).

${ }^{28}$ A. Di Cicco, S. Stizza, A. Filipponi, F. Boscherini, and S. Mobilio, J. Phys. B 25, 2309 (1993).

${ }^{29}$ S. I. Salem, B. Dev, and P. L. Lee, Phys. Rev. A 22, 2679 (1980).

${ }^{30}$ A. Filipponi and A. Di Cicco, Phys. Rev. A 52, 1072 (1995).

${ }^{31} \mathrm{http} / / /$ icsd.ill.eu/icsd/index.html

${ }^{32}$ L. Signorini, L. Pasquini, L. Savini, R. Carboni, F. Boscherini, E. Bonetti, A. Giglia, M. Pedio, N. Mahne, and S. Nannarone, Phys. Rev. B 68, 195423 (2003).

${ }^{33}$ G. Liang, J. Huot, S. Boily, and R. Schulz, J. Alloys Compd. 305, 239 (2000).

${ }^{34}$ F. Boscherini, S. de Panfilis, and J. Weissmuller, Phys. Rev. B 57, 3365 (1998).

${ }^{35}$ G. Apai, J. F. Hamilton, J. Stohr, and A. Thompson, Phys. Rev. Lett. 43, 165 (1979).

${ }^{36}$ A. Balerna, E. Bernieri, P. Picozzi, A. Reale, S. Santucci, E. Burattini, and S. Mobilio, Phys. Rev. B 31, 5058 (1985).

${ }^{37}$ R. E. Benfield, A. Filipponi, D. T. Bowron, R. J. Newport, S. J. Gurman, and G. Schmid, Physica B 208-209, 671 (1995).

${ }^{38}$ Y. Sun et al., Langmuir 22, 807 (2006).

${ }^{39}$ S. Polizzi, P. Riello, A. Balerna, and A. Benedetti, Phys. Chem. Chem. Phys. 3, 4614 (2001).

${ }^{40}$ C. Zlotea et al., J. Am. Chem. Soc. 132, 7720 (2010).

${ }^{41}$ R. Lamber, S. Wetjen, and N. I. Jaeger, Phys. Rev. B 51, 10968 (1995).

${ }^{42}$ S. Krüger, S. Vent, F. Nörtemann, M. Staufer, and N. Rösch, J. Chem. Phys. 115, 2082 (2001). 
${ }^{43}$ P. Lagarde, S. Colonna, A.-M. Flank, and J. Jupille, Surf. Sci. 524, 102 (2003).

${ }^{44}$ J. P. Makongo, Y. Prots, U. Burkhardt, R. Niewa, C. Kudla, and G. Kreiner, Philos. Mag. 86, 427 (2006).

${ }^{45}$ L. Vočadlo, A. Wall, S. C. Parker, and G. D. Price, Phys. Earth Planet. Inter. 88, 193 (1995).

${ }^{46}$ L. Pasquini, A. A. Rempel, R. Würschum, K. Reimann, M. A. Muller, B. Fultz, and H.-E. Schaefer, Phys. Rev. B 63, 134114 (2001).

${ }^{47} \mathrm{~B}$. Ravel and S. Kelly, in Proceedings of the 13th International Conference on X-ray Absorption Fine Structure, edited by
P. Pianetta and B. Hedman, AIP Conf. Proc. No. 882 (AIP, Melville, NY, 2007), p. 150.

${ }^{48}$ G. Bunker, Nucl. Instrum. Methods 207, 437 (1983).

${ }^{49}$ A. Filipponi, J. Phys. Condensed Matter 13, R23 (2001).

${ }^{50}$ B. Ravel, Y.-I. Kim, P. M. Woodward, and C. M. Fang, Phys. Rev. B 73, 184121 (2006).

${ }^{51}$ J. Huot, A. Yonkeu, and J. Dufour, J. Alloys Compd. 475, 168 (2009).

${ }^{52}$ Y. Fukai, The Metal-Hydrogen System (Springer, Berlin, 1993).

${ }^{53}$ J. F. Fernandez, J. R. Ares, F. Cuevas, J. Bodega, F. Leardini, and C. Sánchez, Intermetallics 18, 233 (2010). 